\title{
Soft Computing Technique and Conventional Controller for Conical Tank Level Control
}

\author{
Sudharsana Vijayan ${ }^{\star 1}$, Avinashe $\mathrm{KK}^{2}$ \\ PG scholar, Dept. of Electronics and Instrumentation, Asst. professor, Dept. of Electronics and \\ Instrumentation Vimal Jyothi Engineering College, Chemperi, Kannur, Kerala \\ *Corresponding author, e-mail: sudharsanavijayan@gmail.com¹, Avinashe@vjec.ac.in²
}

\begin{abstract}
In many process industries the control of liquid level is mandatory. But the control of nonlinear process is difficult. Many process industries use conical tanks because of its non linear shape contributes better drainage for solid mixtures, slurries and viscous liquids. So, control of conical tank level is a challenging task due to its non-linearity and continually varying cross-section. This is due to relationship between controlled variable level and manipulated variable flow rate, which has a square root relationship. The main objective is to execute the suitable controller for conical tank system to maintain the desired level. System identification of the non-linear process is done using black box modelling and found to be first order plus dead time (FOPDT) model. In this paper it is proposed to obtain the mathematical modelling of a conical tank system and to study the system using block diagram after that soft computing technique like fuzzy and conventional controller is also used for the comparison.
\end{abstract}

Keywords: Matlab, Fuzzy, PID, Nonlinear System

\section{Introduction}

The control of nonlinear ${ }^{[1]}$ systems has been an significant research topic and many approaches have been proposed ${ }^{[2]}$. In most of the process industries controlling of level, flow, temperature and pressure is a exigent one. They may be classified as linear and non-linear processes based on the plant dynamics. Control of industrial processes is a challenging task for several reasons due to their nonlinear behavior, uncertain and time varying parameters, constraints on manipulated variable, interaction between manipulated and controlled variables, unmeasured and frequent disturbances, dead time on input and measurements.

The control of liquid level in tanks and flow between the tank is a basic crisis in process industries. In level control process, the tank systems like cylindrical, cubical are linear one, but that type of tanks does not provides a complete drainage. For complete drainage of fluids, a conical tank is used in some of the process industries, where its nonlinearity might be at the bottom only in the case of conical bottom tank. The drainage efficiency can be improved further if the tank is fully conical in shape. In many processes such as distillation columns, evaporators, re-boilers and mixing tanks, the particular level of liquid in the vessel is of great significance in process operation. A level that is too high may upset reaction equilibria, cause damage to equipment or result in spillage of valuable or hazardous material. If the level is too low it may have bad consequences for the sequential operations ${ }^{[2]}$.

So control of liquid level is an important and frequent task in process industries. Level of liquid is desired to maintain at a constant value. This is achieved by controlling the input flow. The control variable is the level in a tank and the manipulated variable is the inflow to the tank. Conical tanks find wide applications in process industries, namely hydrometallurgical industries, food process industries, concrete mixing industries and wastewater treatment industries.

The paper is organized as follows: Section I discusses about non linear level process, in Section II and III discusses about experimental setup and modeling of the system and controller design like conventional controller and fuzzy logic controller (FLC), respectively. The simulation results are presented in Section IV. The conclusions are given in Section V. 


\section{Proposed Work}

\subsection{Experimental Setup}

The system used is a conical tank and is highly nonlinear due to the variation in area of cross section. The controlling variable is inflow of the tank. The controlled variable is level of the conical tank. Level sensor is used to sense the level in the process tank and fed into the signal conditioning unit and the required signal is used for further processing.

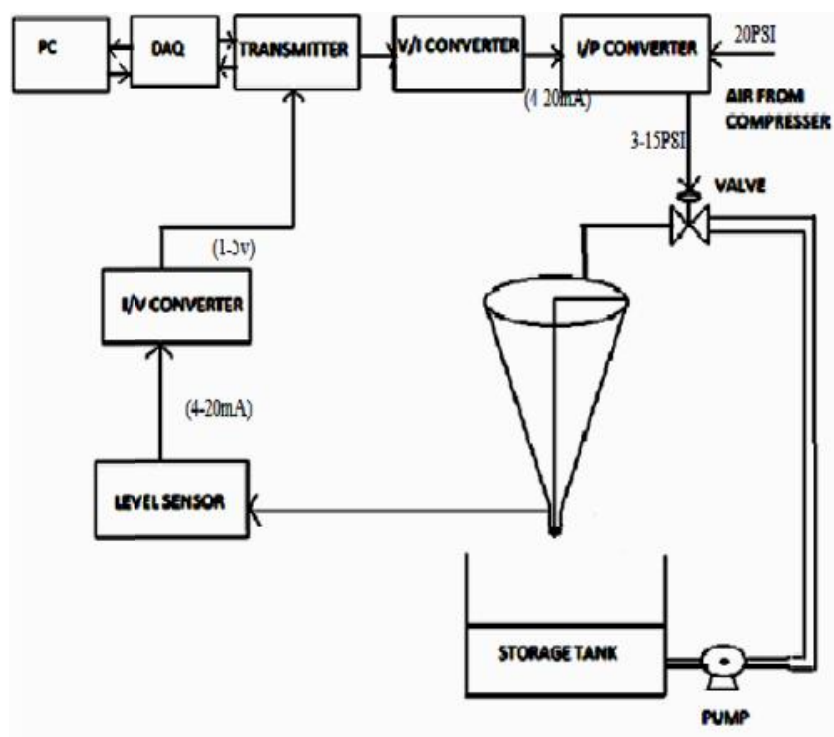

Figure 1. Block diagram of process

The level process station used to perform the experiments and to collect the data ${ }^{[11]}$. One of the computers used as a controller. It consists of the software which is used to control the level process station. The Figure 1 consists of a process tank, reservoir tank, control valve, I to $\mathrm{P}$ converter, level sensor and pneumatic signals from the compressor. When the set up is switched on, level sensor senses the actual level, initially the signal is converted to current signal in the range between 4 to $20 \mathrm{~mA}$. This signal is then given to the computer through data acquisition cord.

Based on the controller parameters and the set point value, the computer will take consequent control action and the signal is sent to the I/P converter. Then the signal is converted to pressure signal using I to $\mathrm{P}$ converter and the pressure signal acts on a control valve which controls the inlet flow of water in to the tank.

Capacitive type level sensor is used to senses the level from the process and converts into electrical signal. Then the electrical signal is fed to the $\mathrm{I} / \mathrm{V}$ converter which in turn produces corresponding voltage signal to the computer. The actual water level storage tank sensed by the level transmitter is feedback to the level controller \& compared with a desired level to produce the required control action that will position the level control as needed to maintain the desired level. Now the controller decides the control action \& it is given to the V/l converter and then to $\mathrm{I} / \mathrm{P}$ converter. The final control element (pneumatic control valve) is now controlled by the resulting air pressure. This in turn control the inflow to the conical tank \& the level is maintained. The tank is made up of stainless steel body and is mounted over a stand vertically. Water enters the tank from the top and leaves the bottom to the storage tank. The System specifications of the tank are as follows chapter. 


\subsection{Mathematical Modelling}

The dynamic behavior [11] of the liquid level $\mathrm{h}$ in the conical storage tank system shown in Figure 2. From the figure,

$$
\begin{aligned}
& \frac{d V}{d t}=\frac{1}{3} \frac{d h}{d t}\left\{A+2 \Pi\left(\frac{R}{H} h\right)^{2}\right\} \\
& F_{\text {in }}-F_{\text {out }}=\frac{1}{3} \frac{d h}{d t}\left\{A+2 \Pi\left(\frac{R}{H}\right)^{2} h^{2}\right\}
\end{aligned}
$$

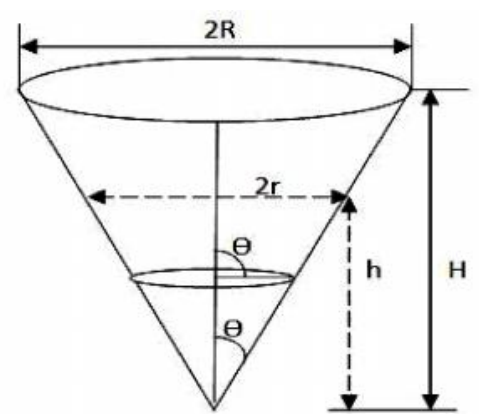

Figure 2. Tank crossection

Output mass flow rate can be written in terms of the exit velocity, $V_{e}$

$$
F_{\text {out }}=a_{e} V_{e}
$$

From mass balance eqn,

$$
\begin{aligned}
& \frac{d m_{e}}{d t}=0=q\left(u_{1}-u_{2}\right)+q\left(\frac{\left(v_{1}-v_{2}\right)^{2}}{2}\right)+q g\left(z_{1}-z_{2}\right)+q\left(\frac{p_{1}-p_{2}}{\delta}\right) \\
& 0=q(0)+q\left(-\frac{v_{2}^{2}}{2}\right)+q g(0)+q\left(\frac{p_{1}-p_{2}}{\delta}\right)
\end{aligned}
$$

Finally,

$$
\begin{aligned}
& \frac{d y}{d t}=-2 \alpha F_{i s} h_{s}^{-3} Y+\alpha h_{s}^{-2} U+\frac{3}{2} \beta h_{s}^{-\frac{5}{2}} Y \\
& \tau\left(\frac{d y}{d t}\right)+y=C U \\
& C=\frac{2 \alpha}{\beta} h_{s}^{\frac{1}{2}} \text { and } \tau=\frac{2}{\beta} h_{s}^{\frac{5}{2}}
\end{aligned}
$$

Taking Laplace transform,

$$
\frac{y(s)}{U(s)}=\frac{C}{[\tau S+1]}
$$




\subsection{Tank Specification}

Height of the tank, $\mathrm{H}=70 \mathrm{~cm}$

Top diameter of the tank, $D=35.2 \mathrm{~cm}$

Bottom diameter of the tank, $d=4 \mathrm{~cm}$

Valve coefficient. $\mathrm{K}=2$

From above data calculate the process gain $(\mathrm{C})$ and time constant $(\mathrm{T})$

Where,

$\alpha=5.035$

$\beta=10.7$

steady state value $h_{s}=10$ (model 1$)$

process gain $\mathrm{C}=3.184$ and time constant $\mathrm{T}=62.81$

so, model $1=\frac{3.184}{62.81 s+1}$

steady state value $h_{s}=20$ (model 2)

process gain $\mathrm{C}=4.472$ and time constant $\mathrm{T}=355.28$

so, model $2=\frac{4.472}{355.28 s+1}$

\section{Controller Design}

\subsection{Controller Tunning}

A proportional-integral-derivative controller (PID controller) is a generic control loop feedback mechanism (controller) widely used in many control systems [5]. A PID controller calculates an error value as the difference between a measured process variable and a desired set point. The controller attempts to minimize the error by adjusting the process control inputs. The PID controller is simple and robust and hence widely used in most of the process industries.

The controller parameters can be tuned using Cohen and Coon method or Ziegler Nichol's method. Cohen [6] and Coon method is commonly referred to as open loop response method for tuning the parameters of conventional controllers.

\subsection{Conventional Controllers}

A PI controller as Figure 3 is commonly used in engineering control system. PI controller calculation involves two separate constant parameters, Proportional and Integral denoted by $\mathrm{K}_{\mathrm{p}}$ and $\mathrm{K}_{\mathrm{l}}$. $\mathrm{P}$ depends on present error and I on the accumulation of past errors [5]. By tuning these two parameters in PI control algorithm the controller can provide desired action designed for specific process requirement. Different tuning rules used for achieving by properly selecting the tuning parameters $K_{p}$ and $\mathrm{T}$ for a PI controller [7].

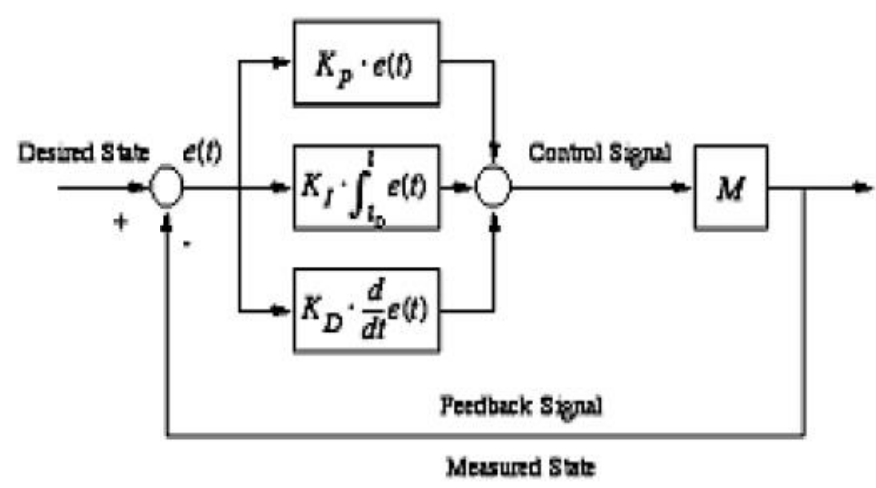

Figure 3. Block diagram of PID controller 
A Proportional Integral Derivative controller (PID) is a generic control loop feedback mechanism widely used in industrial control systems. It is robust due to its strategy to give bounded errors. It was an essential element of early governors and it became the standard tool when process control emerged in the 1940s. In process control today, more than $95 \%$ of the control loops are of PID type, most loops are actually PI control.PID controllers can these days be found in all areas where control is needed.

\subsection{Fuzzy Controller}

MATLAB is a high-performance language for technical computing integrates computation, visualization, and programming in an easy-to-use environment where problems [9] and solutions are expressed in familiar mathematical notation.

This paper presents a simple approach to design fuzzy logic based controller for MATLAB/Simulink environment [10]. It provides tools to create and edit fuzzy inference systems within the framework of MATLAB, and it is also possible to integrate the fuzzy systems into simulations with Simulink. $(U)$ is defined as the output for fuzzy controller. They are fuzzy linguistic variable represent the level error $(e)$, change of level error $(e)$ and the output control effort ( $u$ ) respectively. A fuzzy logic system (FLS) [12] can be defined as the nonlinear mapping of an input data set to a scalar output data.

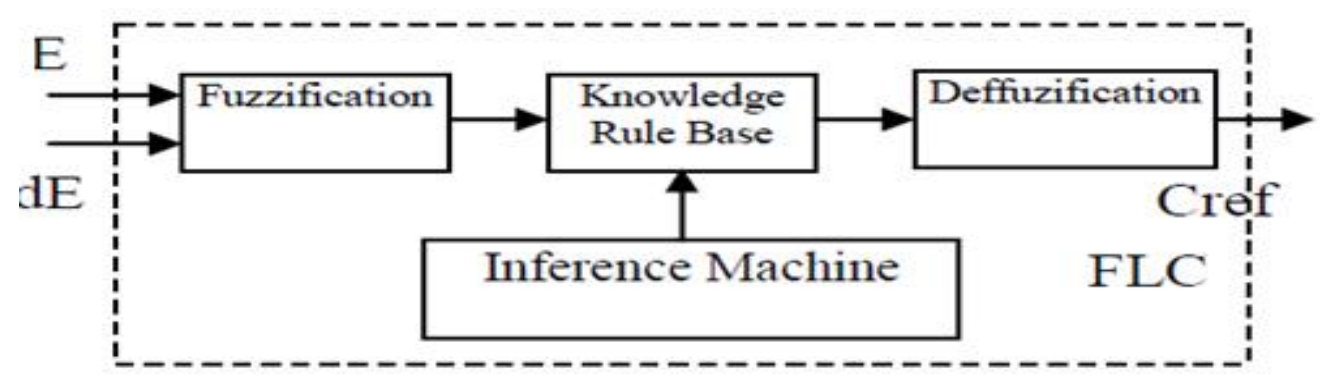

Figure 4. Fuzzy logic system

A FLS consists of four main parts ${ }^{[13]}$ :

- Fuzzifier

- Rules

- Inference engine

- Defuzzifier

These components and the general architecture of a FLS are shown in Figure. The process of fuzzy logic is explained in Algorithm 1: Firstly, a crisp set of input data are gathered and converted to a fuzzy set using fuzzy linguistic variables, fuzzy linguistic terms and membership functions. This step is known as fuzzification. Afterwards, an inference is made based on a set of rules. Lastly, the resulting fuzzy output is mapped to a crisp output using the membership functions, in the defuzzification step [8]. The input and output of the fuzzy controllers are designed below, 


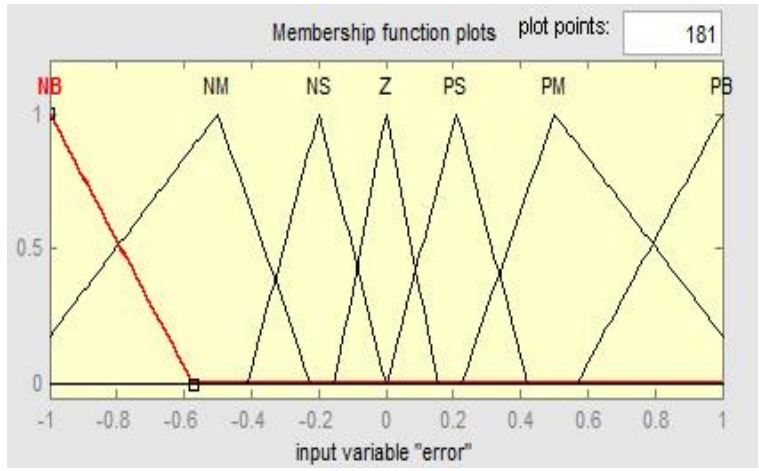

Figure 5. Input variable "error"

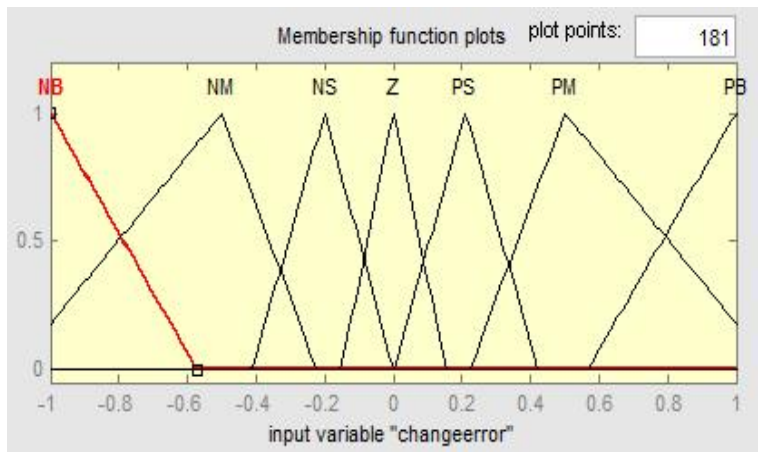

Figure 6. Input variable "change error"

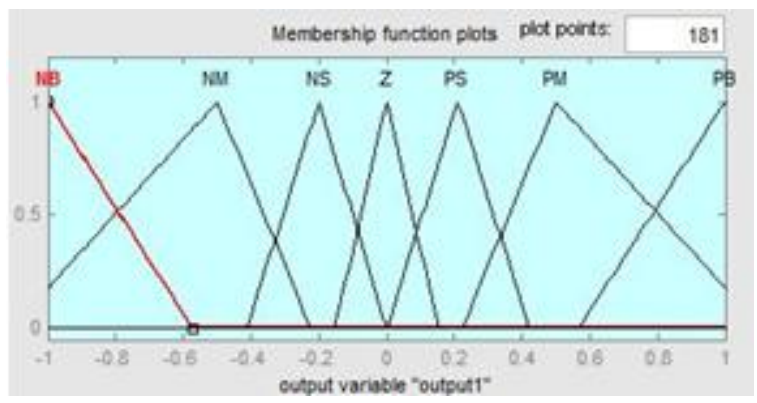

Figure 7. Output variable "output"

Generally fuzzy controller has two inputs like error and change in error. Figure 5 is the membership function of error and Figure 6 is the membership function of change in error. Figure 7 represents the controlling action of the valve.

A fuzzy inference system (FIS) essentially defines a nonlinear mapping of the input data vector into a scalar output, using fuzzy rules. The mapping process involves input/output membership functions, FL operators, fuzzy if-then rules, aggregation of output sets, and defuzzification. 


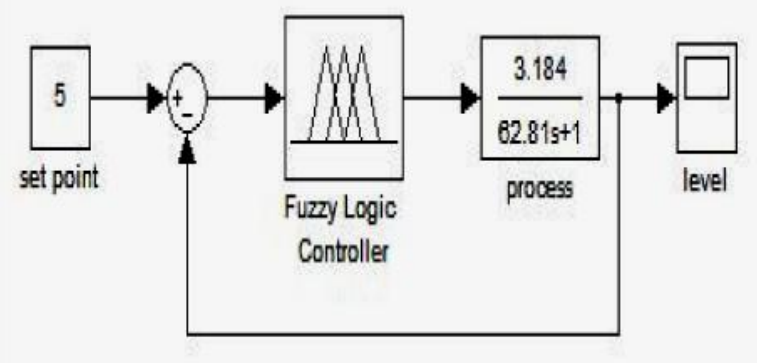

Figure 8. Fuzzy controller system

An FIS with multiple outputs can be considered as a collection of independent multiinput, single-output systems. FIS contains four components: the fuzzifier, inference engine, rule base, and defuzzifier. The rule base contains linguistic rules that are provided by experts [10]. It is also possible to extract rules from numeric data. Once the rules have been established, the FIS can be viewed as a system that maps an input vector to an output vector.

\section{Simulation Result}

At first, the mathematical model of conical tank level process is derived in terms of differential equation and an open loop response is obtained by performing step test in Matlab.

The process is identified and closed loop control performances of various PI and PID controllers were studied and results are presented in figures for two regions. Response and comparison of conventional controllers and fuzzy controllers are shown in Figure 9 and Figure 10.

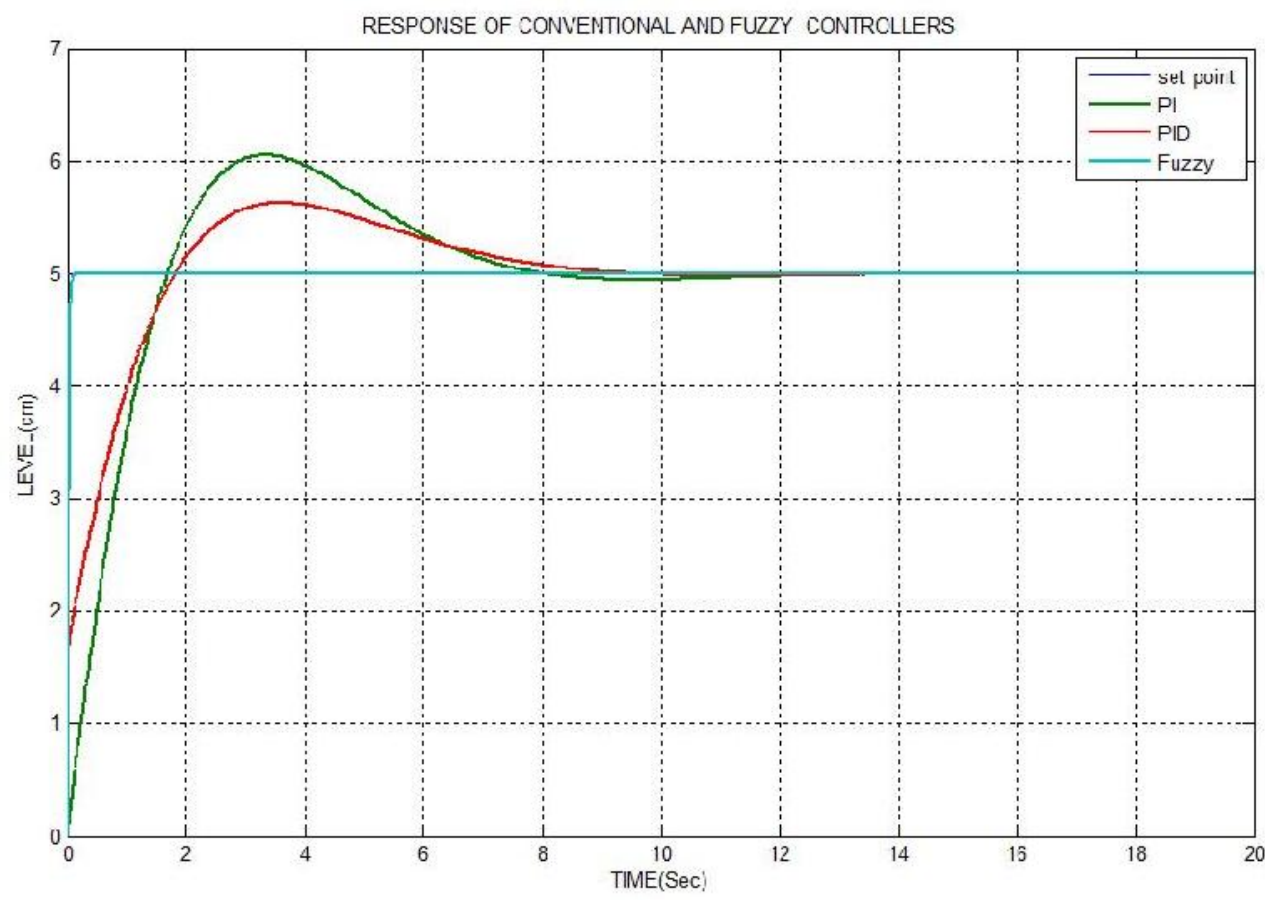

Figure 9. Response of model 1 at setpoint $5 \mathrm{~cm}$ 


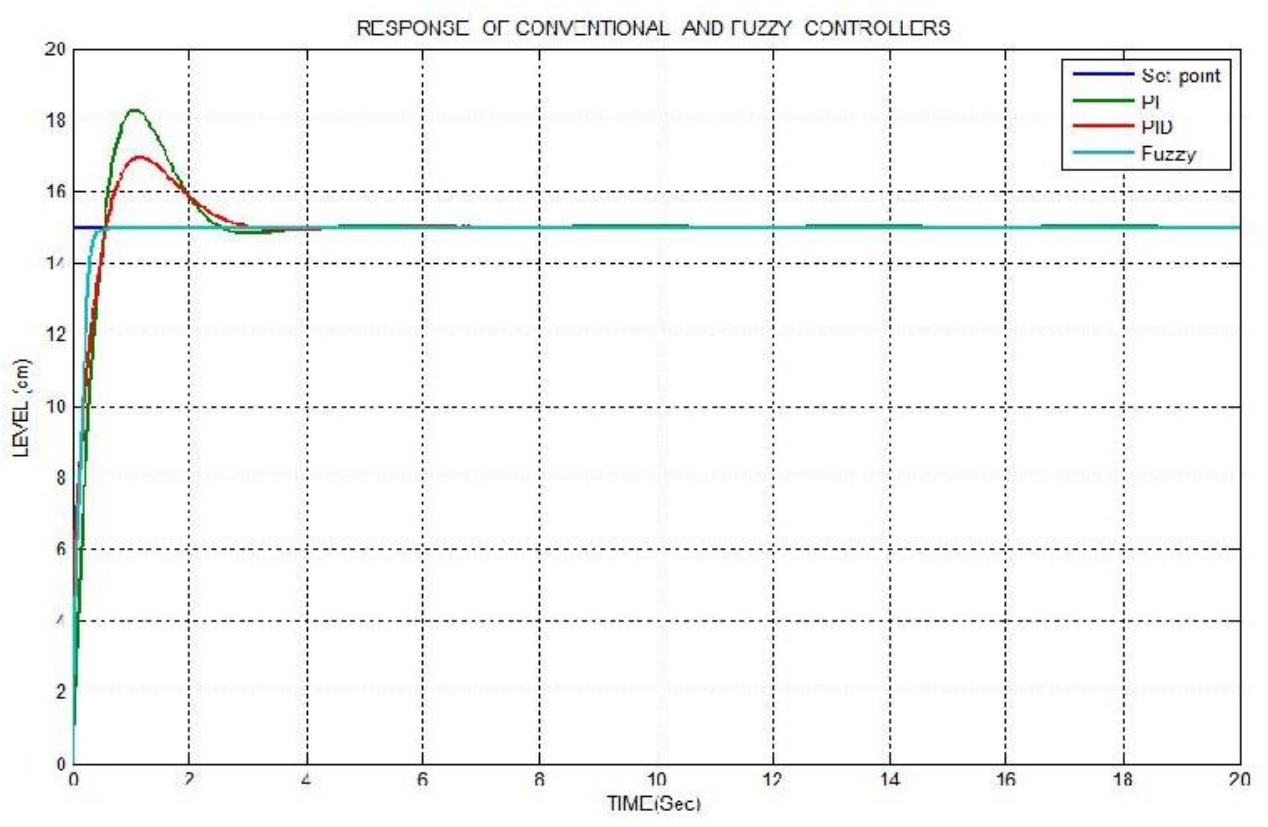

Figure 10. Response of model 2 at setpoint $15 \mathrm{~cm}$

From this response, fuzzy controller fastly tracks the set point than PI and PID controllers. Comparison of controller action like settling time delay time and rise time and errors are shown in Table 1.

Table 1. Comparison of control actions model 1 at setpoint $5 \mathrm{~cm}$ and model 2 at setpoint $15 \mathrm{~cm}$

\begin{tabular}{ccccc}
\hline Model & Controller & Settling time $(\mathrm{sec})$ & Delay Time $(\mathrm{sec})$ & Rise Time $(\mathrm{sec})$ \\
\hline & PI & 13.89 & 0.6328 & 1.6799 \\
1 & PID & 13.37 & 0.3012 & 1.5136 \\
& FUZZY & 1.215 & 0.2352 & 1.4895 \\
& PI & 4.69 & 0.2021 & 0.5316 \\
2 & PID & 4.2195 & 0.0915 & 0.5746 \\
& FUZZY & 0.873 & 0.0751 & 0.4631 \\
\hline
\end{tabular}

Analysis shows in Table 2, the design of fuzzy controller gives a better performance by means of minimum delay time, minimum settling time, minimum rise time and satisfactory over a wide range of process operations.

Table 2. Comparison of errors model 1 at setpoint $5 \mathrm{~cm}$ and model 2 at setpoint $15 \mathrm{~cm}$

\begin{tabular}{ccccc}
\hline Model & Controller & ISE $(\mathrm{sec})$ & IAE $(\mathrm{sec})$ & ITAE $(\mathrm{sec})$ \\
\hline \multirow{4}{*}{1} & PI & 13.44 & 7.152 & 17.76 \\
& PID & 6.15 & 4.893 & 12.73 \\
& FUZZY & 0.3614 & 0.1359 & 0.9207 \\
2 & PI & 39.36 & 7.024 & 5.705 \\
2 & PID & 18.01 & 4.79 & 4.094 \\
& FUZZY & 17.82 & 2.18 & 2.4 \\
\hline
\end{tabular}

The behavior of fuzzy controller is to provide better performance in the case of errors and control actions. 


\section{Conclusion}

The controlling of nonlinear process is a challenging task. The nonlinearity of the conical tank is analyzed. Modelling and transfer function of the system is done by using system identification. Open loop step test method is used to find the proportional gain, delay time and dead time. Here Taylor series approximation is used for the non linear approximation because of accuracy compared to other non linear approximation technique. Conventional controllers like PI \& PID controllers are used as basic controllers; fuzzy controller is also used for obtaining improved performance. Here, after analyzing both simulated response of models, the fuzzy controller is superlative controller than PI and PID controllers.

\section{References}

[1] D Angeline, K Vivetha, K Gandhimathi T Praveena. 'Model based Controller Design for Conical Tank System'. International Journal of Computer Applications. 0975 - 8887. 2014; 85(12).

[2] Anna Joseph and Samson Isaac J. 'Real Time Implementation of Model Reference Adaptive Controller for a Conical Tank'. Proceedings of International Journal on Theoretical and Applied Research in Mechanical Engineering. 2013; 2(1): 57-62.

[3] T Pushpaveni, S Srinivasulu Raju, N Archana, M Chandana. 'Modeling and Controlling of Conical tank system using adaptive controllers and performance comparison with conventional PID'. International Journal of Scientific \& Engineering Research, ISSN 2229-5518. 2013; 4(5): 629.

[4] K Sundaravadivu, K Saravanan and V Jeyakumar. "Design of Fractional Order PI controller for liquid level control of spherical tank modeled as Fractional Order System”. IEEE, ICCSCE, Malaysia. 2011: $522-525$.

[5] Marshiana D and Thirusakthimurugan P. 'Design of Ziegler Nichols Tuning controller for a Non-linear System'. Proceedings of International Conference on Computing and Control Engineering. 2012: 121-124.

[6] Abhishek Sharma and Nithya Venkatesan. 'Comparing PI controller Performance for Non Linear Process Model'. Proceedings of International Journal of Engineering Trends and Technology. 2013; 4(3): 242-245.

[7] H Kiren Vedi, K Ghousiya Begum, D Mercy, E Kalaiselvan. "A Comparative Novel Method of Enhanced Tuning of Controllers for Non-Linear Process”. National System Conference. 2012.

[8] A Short Fuzzy Logic Tutorial April 8, 2010

[9] Fuzzy control programming. Technical report, International Electrotechnical Commision. 1997.

[10] J Mendel. Fuzzy logic systems for engineering: a tutorial. Proceedings of the IEEE. 1995; 83(3): 345377.

[11] Rajesh T, Arun Jayakar, Siddharth SG. "Design and implementation of IMC based PID controller for conical tank level control process". International Journal of Innovative Research in Electrical, Electronics and Instrumentation and control Engineering. 2014; 2(9).

[12] Tutorial on fuzzy Logic.

[13] Marcelo Godoy Simoes, Colorado School of Mines Engineering Division 1610 Illinois Street Golden, Colorado 80401-1887 USA "Introduction to fuzzy control". 